\title{
The use of buccal mucosa graft for correction of severe chordee and urethroplasty in proximal hypospadias repair
}

\author{
Smail Acimi ${ }^{1}$ (D)
}

Received: 12 November 2018 / Accepted: 15 November 2018 / Published online: 20 November 2018

c) Springer-Verlag GmbH Germany, part of Springer Nature 2018

\section{Dear Editor,}

I would like to congratulate Djordjevic ML et al. [1] for their remarkable paper.

The proximal forms of hypospadias represent approximately a third of cases and are very often associated with curvatures. The essential factor responsible for this curvature is the fibrosis tissue present on the ventral side of the penis. However, when the initial curvature is $>90^{\circ}$, a short urethral plate becomes the main cause of this curvature. The curvatures by corporeal disproportion are rare and give a slight curvature [2]. Thus, it is not necessary to open ventrally the tunica albuginea for penile straightening, and a simple section of the urethral plate at the corona and its release from corpus cavernosum continued upstream from meatus, usually lead to correction of the penile curvature.

The ideal surgical technique in hypospadias repair should be easy to perform, which corrects the deformation while preserving the function of the penis, and which gives few or no postoperative complications. The penis of the young child is small, and I think that there is always a solution with the use of penile skin, even for severe forms.

It is widely accepted that pedicle flaps are the best, and the free grafts urethroplasty can only be proposed if it is impossible to have a pedicle flap. Among the substitution tissues, the oral mucosa graft is the most commonly used. It is available in all patients, easy to harvest, and hairless. However, the buccal mucosa is now routinely used in urethral stricture repair, more rarely in hypospadias.

The penile skin, as the skin of the eyelid, is special; it does not resemble any other skin of the human body. It is more flexible and more extensible, and it is devoid of subcutaneous tissue, which gives it the ability to considerably stretch

Smail Acimi

acimi_smail@yahoo.fr

1 Department of Visceral Surgery, Children's Hospital

Canastel, University of Oran, Oran, Algeria during erection. In addition, the growth of the penis skin depends on androgens secretion. Thus, it is irreplaceable.

One of the main reasons for dissatisfaction of penile appearance at the adult age of patients who underwent hypospadias surgery in childhood is the residual or recurrent curvature of the penis [3]. A significant number of adults and adolescents who we continue to follow, patients who, at their young age underwent onlay island flap urethroplasty with or without mobilization of the urethral plate and dorsal plication, report the presence of curvature during erection. I think that the reappearance of the curvature after a few years is due to poor growth of the urethral plate preserved, and the use of the oral mucosa on the ventral side of the penis can behave as a preserved urethral plaque, and can be responsible for reappearance of penile curvature in adulthood.

Author contributions A: manuscript writing/editing.

\section{Compliance with ethical standards}

Conflict of interest The author declares no conflicts of interest and has nothing to disclose.

Research involving human participants and/or animals None.

\section{References}

1. Djordjevic ML, Bizic M, Stojanovic B, Bencic M, Kojovic V, Korac G (2018) Buccal mucosa graft for simultaneous correction of severe chordee and urethroplasty as a one-stage repair of scrotal hypospadias (watch technique). World J Urol. https://doi. org/10.1007/s00345-018-2517-y (Epub ahead of print)

2. Acimi S, Acimi MA (2017) Can we preserve the urethral plate in proximal hypospadias repair? Ann Plast Surg 79:68-72

3. Acimi S (2018) Commentary: results of onlay preputial flap urethroplasty for the single-stage repair of mid-and proximal hypospadias. Front Pediatr 14(6):129 